\title{
Desde lo trágico hacia lo amoroso. Lo comunitario en Kierkegaard
}

Matías Tapia Wende

Universidad de Chile - Conicyt

7510192 Santiago (Chile)

tapiawende@gmail.com

\begin{abstract}
This article aims to examine the links in Kierkegaard's thought between his early aesthetic comprehension of tragedy and his view of community. The thesis to be defended is that certain categories related to the Kierkegaardian concept of aesthetic tragedy are later assumed under the notion of immediacy crossed by reflection. For Kierkegaard, these categories are deployed existentially through the exercise of love.
\end{abstract}

Keywords: Tragedy, community, modernity, Kierkegaard.
Resumen: Este artículo pretende revisar los vínculos que existen entre una comprensión estética temprana de la tragedia y una modulación comunitaria en Kierkegaard. La tesis a considerar es que se pueden leer en un registro estético kierkegaardiano de lo trágico ciertas categorías que luego van a ser asumidas en una inmediatez cruzada por la reflexión y que significarán existencialmente la etapa resolutoria del devenir individual en el amor al prójimo.

Palabras clave: Tragedia, comunidad, modernidad, Kierkegaard. 
E n la introducción al volumen XIV del International Kierkegaard Commentary, dedicado a Una reseña literaria (1846), texto en el que está incluido el apartado La época presente, Robert Perkins destaca la potencia de un mito ya tradicionalmente extendido, a saber, aquel que asegura que "Kierkegaard desarrolla su concepto del individuo en un vacío social y político". La interioridad kierkegaardiana, que fuera expuesta por Adorno como una "interioridad sin objetivo" 2 , ha sido interpretada casi de suyo a partir de su variante religiosa más extrema, que inevitablemente decanta en un despojar al sujeto de sus vínculos comunitarios y desde ahí en un tener por fallido el análisis del individuo en Kierkegaard ${ }^{3}$.

Lévinas sigue esta línea en una de sus pocas referencias extensas a Kierkegaard. En Nombres propios (1976), se encuentra una reelaboración de las intervenciones de Lévinas en la discusión que se dio en torno a la celebración del ciento cincuenta aniversario del nacimiento de Kierkegaard en 1964 en París. En dicha instancia, Jean Hyppolite puso sobre la mesa la cuestión de la molestia que podía generar el pensamiento kierkegaardiano. A esto contestó Lévinas desarrollando dos puntos que le perturban de Kierkegaard ${ }^{4}$. El primero radica en que Kierkegaard, en su rehabilitación novedosa de la subjetividad frente a la absorción de la universalidad hegeliana, "legó a la historia de la filosofía una subjetividad exhibicionista y deshonesta", que "en su deseo de evitar perderse a sí misma en el universal, rechaza toda forma" ${ }^{5}$. Para Lévinas, y es éste el segundo punto de su contrariedad con Kierkegaard, de esta afrenta teórica a la filosofía emerge un lenguaje particularmente violento, que "no teme ni el escándalo ni la destrucción" y que se convierte, primero

1. R. PERKINS (ed.), International Kierkegaard Commentary: Two Ages (Macon, Mercer, 1984) xiii.

2. TH. Adorno, Kierkegaard. Construcción de lo estético, Obras completas (Akal, Madrid, 2006) Tomo II, 44.

3. Cf. R. PERKINS (ed.), op. cit., xiv.

4. Cf. E. LÉvinas, Proper Names (Stanford University Press, Stanford, 1996) 76.

5. Ibidem.

6. Ibidem. 
en Kierkegaard que en Nietzsche, en una manera de hacer la filosofía. Llevando esta lectura al borde de la polémica, Lévinas cree anticipar en la expresión filosófica kierkegaardiana "los ecos de ciertos casos de violencia verbal que dicen ser escuelas de pensamiento"7, entre ellas el nacionalsocialismo. El origen de esta severidad lo cifra Lévinas en la trascendencia a la ética que opera la constitución religiosa del individuo en Kierkegaard, que se ve con unilateral claridad en Temor y temblor (1843). Efectivamente, si asumimos cierta parcialidad como perspectiva, en Kierkegaard se da una confrontación con la filosofía especulativa, que asume luego la subjetividad como "el cuidado que un ser toma por su propia existencia", y que gestiona con esto una ruptura con la generalidad ética en orden a proteger la singularidad del yo, mesurando la pérdida que significaría su supeditación a una regla general. Así, de acuerdo con Lévinas, el ánimo de Kierkegaard de trascender el estadio ético tiene que ver con la falta de una experiencia concreta, aquella que explicita que "la ética como consciencia de una responsabilidad hacia los otros, lejos de perderte en la generalidad, te singulariza, te pone como un individuo único, como un yo" 9 .

Deslindándonos de esta posición tradicional, sostenemos que en Kierkegaard es abiertamente reconocible una impronta éticopolítica, impulsada por el ímpetu de terminar con la segregación de conciencia que había asentado la filosofía y que habían contribuido a resguardar las estructuras religiosas y de gobierno. Asumiendo que el blanco de su polémica era la multitud como destructora del sujeto, Kierkegaard se sentía movido moralmente a "hacer a los hombres conscientes, de tal modo que no desperdicien ni despilfarren sus vidas"10. La necesidad de este despertamiento era relevada por el dominio aristocrático y por la complicidad de las esferas de poder en la conservación de la masa. Esta "iniquidad de la exclusividad de los

7. Ibidem.

8. Ibidem.

9. E. LÉVINAS, Proper Names, op.cit., 76-77. Énfasis del texto.

10. S. KIERKEGAARD, Søren Kierkegaard's fournals and Papers. 7 vols. (Indiana University Press, Bloomington, 1967-1978) VIII 1 A 23. En adelante JP: VIII 1 A 23. 
aristócratas"11 mantenía a raya la odiosa situación que significaría, dice Kierkegaard, que la gente se hiciera consciente. Esta conciencia, ahora desde el aparato metafísico, no es otra cuestión que la potencia configuradora de subjetividad, que sigue un determinado proceso constitutivo dialéctico y que se repite ulteriormente en la articulación comunitaria del singular con los otros.

Con la reapropiación como criterio de guía, la tesis que sostendrá este artículo es que se pueden leer en una modulación estética kierkegaardiana de lo trágico ciertas categorías que luego van a ser asumidas en una inmediatez cruzada por la reflexión. En medio de la sucesión de estadios de la existencia que plantea Kierkegaard, nos parece que se puede avisar la reapropiación de una cierta disposición trágica que se vuelve en último término una condición necesaria para el advenimiento convivencial originario. Este despliegue se justifica en el levantamiento inicial de la conciencia que representa lo trágico y que conforma para Kierkegaard el germen a partir del que en sucesión se comienza a ejecutar una singularidad auténtica y que desde ahí autentifica a las demás singularidades.

El trasfondo que sostiene esta propuesta se gesta en función de la repetición en Kierkegaard de un movimiento filosófico tradicional: el de derivar un desenvolvimiento ético a partir de un sostén metafísico. Con esto, nos acercamos a Patricia Cutting, que defiende una reversión de la estructura de los estadios kierkegaardianos desenvuelta en dos líneas: una concreta y otra abstracta. La modulación concreta se mueve en el nivel óntico, describiendo las actualizaciones de diversas categorías en varios individuos en un determinado nivel existencial. Por su parte, la modulación abstracta describe y analiza las estructuras ontológicas fundamentales que sostienen la proyección en lo concreto $^{12}$. En esta línea, la posibilidad, devenida al mismo tiempo necesidad, de un desborde del individuo hacia los otros surge en el seno mismo de la dialéctica subjetiva.

\section{Ibidem.}

12. Cf. P. CutTing, The Levels of Interpersonal Relationships in Kierkegaard's Two Ages, en R. Perkins (ed.), International Kierkegaard Commentary: Two Ages (Mercer University Press, Macon, 1984) 74. 
Estructuraremos la exposición en tres partes. En la primera, daremos cuenta de la revisión estética de la tragedia que nos entrega Kierkegaard en el ensayo El reflejo de lo trágico antiguo en lo trágico moderno, contenido en el primer tomo de $O$ lo uno o lo otro (1843). De este breve opúsculo sacaremos, más que determinaciones literarias sobre la tragedia, categorías existenciales que recusan para el mismo Kierkegaard el impacto espiritual de lo trágico, sobrepasando con creces los límites de la pura producción. Luego, con estas delimitaciones a cuestas, revisaremos el desenvolvimiento del brote que emerge en lo trágico, desplegando la estructura de la subjetividad kierkegaardiana a partir de su configuración dialéctica. Por último, y como conclusión y apuesta, argumentaremos que la clave que sostiene a esta subjetividad devenida auténtica conlleva el desbordamiento de la singularidad hacia una comunidad en movimiento, en perpetua repetición, en incesante dependencia de sus componentes.

Midiendo lo que significa nuestro proyecto de lectura, es preciso hacer la salvedad de que nos movemos en un campo de interpretaciones y de tensiones de los conceptos y de los aparatos teóricos, por lo que proponemos en última instancia un ejercicio hermenéutico que se intenta responsable, pero que se asume también como abierto.

Cyde Holler considera El reflejo de lo trágico antiguo en lo trágico moderno como "quizás la más fina contribución de Kierkegaard a la estética" ${ }^{13}$. Este breve ensayo, empapado de una cercanía intelectual profundísima con el pensamiento griego e imbuido además por los debates en torno al romanticismo de Schlegel y a la interpretación hegeliana de la tragedia, tiene dos partes claramente distinguibles. Kierkegaard comienza discutiendo sobre la tragedia antigua y el malentendido que en relación con ella supone la tragedia moderna,

13. C. Holler, Tragedy in the Context of Kierkegaard's Either/Or', en R. PERKINS (ed.), International Kierkegaard Commentary: Either/Or, I (Mercer, Macon, 1995) 125 . 
para luego proyectar su propia versión de lo que sería una tragedia en la modernidad, conservando la disposición del concepto. Nos interesa hacer una revisión detallada de este doble movimiento, en tanto que en él se decantan categorías esenciales para nuestro análisis posterior.

Revisando la noción de tragedia antigua, Kierkegaard apunta que, si bien la forma aristotélica de la tragedia se puede aplicar en su cierto espectro estético, el contenido con el que ella puede llenarse varía "dependiendo de la diversidad de representaciones de lo trágico dadas en la conciencia universal"14. Lo que Kierkegaard busca, entonces, no es tanto la relación entre lo trágico antiguo y lo moderno, sino la particularidad de lo trágico antiguo que permite ser integrada en lo trágico moderno. Y con esto, que "lo verdaderamente trágico se haga visible" ${ }^{15}$.

Kierkegaard apunta que para Aristóteles la individualidad no actúa para representar caracteres en la acción trágica, sino que estos son incorporados en función de la acción. Lo propio de la tragedia antigua es que la acción no tiene su emergencia en el puro carácter, cuestión que encierra un cierto grado de pasividad. El prisma que para Kierkegaard condiciona esta lectura es que los antiguos no contaban con la subjetividad reflejada sobre sí misma. A pesar de que el individuo se moviera con libertad, era sostenido por superestructuras sustanciales: el Estado, la familia, el destino. En este registro, la acción es a la vez pasión. En la modernidad, en cambio, toda influencia o padecimiento es reducida a la acción. Abandonando con esto la inmediatez, Kierkegaard proyecta la imagen del héroe sosteniéndose y cayendo por sus propias obras. Este nuevo panorama le da el pie para desplegar una diferencia esencial entre lo antiguo y lo moderno, a saber, el género que envuelve la culpa trágica. La bamartía $^{16}$ del trágico en la antigüedad es un punto intermedio entre

14. S. KierkegaARD, O lo uno o lo otro (Trotta, Madrid, 2006) 160. En adelante EM, 160. S. KieRKEgAard, Enten-Eller. Søren Kierkegaards Skrifter (Søren Kierkegaard Forskningscenteret, Copenhague, 1997) Tomo II, 141. En adelante SKS II, 141.

15. OO, Ibidem/SKS II, 142.

16. Holler propone que en cierto sentido El reflejo de lo trágico antiguo en lo trágico 
actuar y padecer, mientras que en el aislamiento subjetivo de la modernidad se eleva, en esa soledad precisamente, la impronta ética de la culpa. No obstante, se presenta aquí un germen de inadecuación, dice Kierkegaard. Si en la tragedia no hay culpa o hay culpa absoluta, lo trágico se difumina. Así, justamente en esta fatalidad encarnada en la subjetividad obrante se opera un malentendido que subyace a la época moderna misma. El eje estético de la modernidad, que es leído por Kierkegaard en los albores de su desarrollo de la dialéctica individual, radica en lo cómico, en el aislamiento. La tensión se da en que cuando lo trágico trata de disponerse sobre estas tablas, se convierte más bien en un mal o una vileza, sin que se dé la ambigüedad constitutiva de lo trágico, es decir, que el héroe sea culpable e inocente a la vez.

La determinación de la culpa revertida afecta a la estructura literaria de la tragedia: el monólogo deviene diálogo y la acción es absorbida por la situación. Asimismo, se altera el estímulo que genera la tragedia en el estado de ánimo del espectador. Volviendo a Aristóteles, y confirmándose con algunos matices en Hegel, Kierkegaard se encuentra con las exigencias del temor y la compasión. El temor lo tiene como aquella apertura que se da en cada caso particular y a la compasión la dispone como la inclinación que "constituye la impresión definitiva"17. Con una perspicacia especulativa bastante afinada, Kierkegaard sabe que es de este estado de ánimo compasivo del que debe valerse, justamente porque encarna la misma dialéctica entrañada en la culpa trágica. Esta elasticidad, reconocida por Hegel como la "verdadera compasión" (wabrhaftes Mitleiden) $)^{18}$, releva bajo el prisma kierkegaardiano la disparidad en la culpa trágica. Seña-

moderno puede ser entendido como una interpretación de la ambigüedad constitutiva que señala Aristóteles para la hamartía del héroe trágico. Nos parece que debe hacerse la concesión, en todo caso, de que Aristóteles hablan por momentos en registros distintos. Cf. ARISTóteles, Poética (Gredos, Madrid, 1974) 1453a.

17. OO, 166/SKS II, 147.

18. G. W. F. Hegel, Vorlesungen über die Aesthetik (Druncker und Humblot, Berlin, 1838 ) tomo III, 532. Citado por S. KierKEGAard en OO, 166 / SKS II, 147. Además del buen recuento en torno a la influencia de Hegel en El reflejo de lo trágico antiguo en lo trágico moderno, que hace Holler en el artículo que hemos citado arriba, recomendamos encarecidamente revisar J. STEWART, Kierkegaard's Relations to Hegel Reconsidered (Cambridge University Press, Cambridge, 2003) 218-225. 
lando subrepticiamente los niveles iniciales de la conciencia estética, Kierkegaard denota que en la tragedia antigua la pena (Sorg) tiene una profundidad mayor que el dolor (Smerte). La sustancialidad, el embargo corporal casi inmediato de la pena se contraponen con la hondura reflexiva que envuelve el dolor ante el sufrimiento. Estas diferencias de categorías, exactas o no dentro del discurso psicológico y clínico contemporáneo, le ayudan a Kierkegaard a rastrear de nuevo la ambigüedad estética que se juega en la tragedia antigua y que la modernidad suprime ante la individualidad reconstituida. El vínculo se debate en que "cuanto más se acusa la idea de culpa, mayor es el dolor y menos honda la pena"19. El escalón de conciencia que le corresponde a la tragedia antigua confirma en efecto que la pena se vuelva la piedra de toque de la experiencia trágica, toda vez que se asume y se conserva esa contradicción originaria en que el héroe aparece como culpable y como inocente a un tiempo. Por su parte, la modernidad aviva la afectación dolorosa, para la que el castigo de los dioses no es ni ínfimamente comparable con el sufrimiento de la culpa con que carga el héroe que es transparente a sí mismo y paciente de todo su yerro. Esta transparencia se declama para Kierkegaard en otro estadio de conciencia y, por lo mismo, de cualidad, esto es, el dolor más cruento se expresa como arrepentimiento, tendencia que tiene un cariz de suyo ético. Este impulso, no reconocido en la pérdida de sustancialidad de lo moderno, despeja del plano la compasión, precisamente porque se asume la claridad de conciencia con la que el individuo debería apropiar su acción. Sin el contraste que daba la compasión, se pierde tanto el sentido subjetivo como el objetivo en que se desplegaba el concepto de lo propiamente trágico.

La pena verdaderamente estética, la pena de la tragedia antigua, se caracteriza por conservar siempre un componente de culpa, pero que no es asumido del todo por la reflexión subjetiva. En todo caso, y por mor del concepto mismo, hay ciertos rastros de dolor, que se ven, por ejemplo, en Filoctetes ${ }^{20}$, cuando éste se lamenta por su des-

19. OO, 167/SKS II, 147.

20. Cf. OO, 169/SKS II, 150. 
tino y hace surgir en un despertamiento de la conciencia subjetiva la contradicción interna en la que se está apostando su individualidad. En esta constitución trágica, Kierkegaard desliza una sinergia entre pena y dolor como constitutivos de la experiencia trágica originaria, que tiene un estrecho vínculo con el desenvolvimiento de la conciencia, esto es, que en lo trágico siempre debe darse la pena y la culpa, por un lado, y el dolor y la inocencia, por otro. Aquí se juegan la transparencia en la pena y la oscuridad en el dolor, haciendo surgir con renovada fuerza el engranaje dialéctico que se opera en la ambigüedad trágica estética.

De esto emerge una diferencia que es esencial para nuestra cuestión. La conformidad de la inocencia y de la culpa trágicas, instanciadas en el desenvolvimiento trágico, que no estamos analizando únicamente desde su cariz literario, sino también existencial, suponen la relativización de un principio de absolutidad que es con todo metafísico. Con esto arriba Kierkegaard a un gesto fundamental: la vida de Cristo puede ser vista como una tragedia desde el punto de vista metafísico, pero no desde el estético. Esto se asienta en que la relativización de la estética no expresa "la absoluta identidad de una acción absoluta y de un padecimiento absoluto" ${ }^{21}$, identidad que se da con Cristo, en tanto que en su figura se concentran el padecimiento total y la obediencia total. Esta categoría de absoluto dada en la acción será capital para desplegar una lectura de la elasticidad trágica, resignificada luego en el advenimiento de la inmediatez cruzada por la reflexión.

Otro elemento central reflota en la segunda parte del ensayo de Kierkegaard. Llegado el punto en que ha mostrado que la tragedia moderna se ha sostenido sobre un malentendido, Kierkegaard se propone crear su propio personaje trágico con las marcas de la modernidad, pero asumiendo al mismo tiempo lo primordial que envuelve el concepto mismo de la tragedia. A su heroína ficticia la llama Antígona, conservando el apego a lo clásico en esta reversión en lo moderno. Escoge esta figura femenina, la "hija de la pena"

21. OO, 168/SKS II, 149. 
que provee con la "dote del dolor"22, precisamente para obtener de ella la sustancialidad y la reflexión, fuentes ambas de lo penoso y lo doloroso. Este vaivén entre pena y dolor encarna prístinamente lo que para Kierkegaard representa el despertamiento de la conciencia, pues aunque no se da todavía una reflexión infinita que en su infinita subjetividad sustraiga toda la pena del dolor, sí se ejecuta la disposición penosa y desde ella el advenimiento intermitente del acuse doloroso.

Kierkegaard parte de los presupuestos griegos: la irritación de los dioses contra la estirpe de Lábdaco; la muerte de la Esfinge a manos de Edipo y la consecuente liberación de Tebas; el patricidio de Edipo y las nupcias con Yocasta, vínculo del que nace Antígona ${ }^{23}$. Y aquí introduce la variante. Detrás del honor y la admiración con que vive Edipo luego de haber matado a la Esfinge y haber liberado a Tebas, hay una porción de oscuridad. Este secreto ajeno a todos es posesión de Antígona. Centrándose en la importancia de la trama, así como de la situación, Kierkegaard remarca que no tiene importancia saber cómo llegó el secreto a Antígona. Lo que interesa es ver el avance paulatino desde el presagio hasta la certeza, desde la conmoción pasajera hasta la angustia. Esta categoría, en ciernes todavía en la terminología kierkegaardiana, es alzada aquí por Kierkegaard como una determinación propia de la modernidad, que conserva no obstante su impronta trágica. El asunto es que la angustia es reflexión y, por lo mismo, se aleja del campo de acción de la pena. En cierto sentido, la angustia es la que instancia la pena en el corazón y la fija profundamente, en un movimiento de repetición que tiene que agenciarse cada vez en este nivel inicial de levantamiento de la conciencia. La angustia contempla y desea la pena, a la vez que la teme y la repele. En esta ambigüedad recae la pertenencia trágica de la angustia para Kierkegaard, precisamente reflejando esa dualidad entre inocencia y culpa que se desplegaba en lo antiguo. Con todo, la angustia agrega además una salida a la inmovilidad del presente, en tanto que ilumina con su halo angustiante hacia el pasado o hacia

22. OO, 171/SKS II, 152.

23. Cf. OO, 172/SKS II, 153. 
el futuro. La pena de los griegos, leída bajo el prisma de suyo moderno de Kierkegaard, no tenía la posibilidad de una proyección más allá del instante.

A diferencia de la Antígona clásica, la Antígona que modela Kierkegaard no vive "volcada hacia afuera sino hacia adentro" 24. En su incipiente reflexión se arma la guarida para la retención del secreto, para la asunción del destino desdichado de su padre, que porta con orgullo como si fuera un signo de bienaventuranza y que le otorga en el silencio un cariz sobrenatural a su subjetividad. Su interioridad se blinda ante los oídos ávidos de los hombres y, a pesar de tener tanto que decir, calla en la potenciación de su espíritu. La Antígona moderna se alegra en su pena y la vive en efecto desde la movilidad que le imprime la reflexividad, es decir, con dolor y desde el dolor ${ }^{25}$.

Tanto la Antígona griega como la moderna participan de la culpa de su padre "mediante su piedad infantil" 26 , pero aquella lo hace asumiendo que la responsabilidad y sufrimientos paternos son hechos externos, mientras que esta se apropia del peso culposo del padre de una forma totalmente otra. Kierkegaard invita a plantear esta cuestión suponiendo que Edipo ha muerto. En vida, Antígona nunca compartió con su padre el secreto que de él ella guardaba. Con la muerte de Edipo, entonces, se esfuma cualquier posibilidad para que Antígona se libere de su silencio. No está dentro de las opciones compartir el secreto con otra persona, toda vez que la honra de su padre se pondría inevitablemente en juego. Así, la vida de la Antígona moderna cobra sentido y fuerza en este sostenimiento de su interior, en el amor inquebrantable al padre y en la encarnación gratuita de su culpa. Ahora, lo moderno, la "anfibología de su dolor" ${ }^{27}$, se presenta con claridad meridiana en una configuración tensa: Antígona no pudo disfrutar del reposo de penar junto a su padre, ensalzando su amor y la lealtad que guardaba hacia su culpa. Antígona no sabe si su padre conoce su propio secreto. En esta ten-

24. OO, 173/SKS II, 154.

25. Cf. OO, 174/SKS II, 155.

26. OO, 178/SKS II, 159.

27. OO, Ibidem/SKS II, Ibidem. 
sión interior, con la que ella carga como instanciación individual de la sustancialidad familiar, la Antígona moderna se mueve en las ascuas del doloroso secreto, en la apropiación repetida de la pena que no la aflige en cuanto la reflexión la aviva a interiorizarla.

Con esto desplegado y con la subjetividad de la Antígona moderna construida, Kierkegaard introduce el sesgo de la colisión explícitamente trágica. Antígona, con la amplitud pasional de su interioridad confirmada en la fuerza con que se apega a su secreto, cae mortalmente enamorada. El conflicto está en que Antígona carga con la dote inusual de su dolor guarecido en torno a su subjetividad, inseparable de ella y en inevitable pugna con la nueva reclamación de su amor. En una doble colisión, primero entre el secreto de su padre y su lealtad hacia él, y luego entre su resolución de honrar lo paterno y su amor simpatético hacia el amado, Antígona se desdobla en una homogeneidad de poderes que la tensan hacia la traición de su secreto. Sobre este edificio hegeliano ${ }^{28}$, Kierkegaard asume que la salida de su heroína se juega únicamente en la muerte, allí donde podrá pertenecerle al amado en el preciso instante en que ella le sea arrebatada para siempre y no por otra razón que el recuerdo del padre y su culpa.

La interioridad de esta Antígona moderna se vuelve de este modo una de las fuerzas que colisionan en el conflicto trágico, asumiendo la determinación plena del concepto en su ambigüedad estética, pero rescatando a la vez la posibilidad de ahondar en la interioridad, en la movilidad del dolor, desde aquella dualidad constitutiva.

\section{III}

Para conservar el germen de subjetividad que se despierta en el entramado trágico estético que construye Kierkegaard y para desde ahí proyectar una reapropiación reflexiva de la inmediatez al devenir el individuo auténtico, nos asiremos de tres modulaciones en las que podremos encontrar un pie de apoyo y que tomaremos como pequeñas hojas de ruta.

28. Véase nota 17. 
En primera instancia, tendremos a la vista la aserción de George Steiner de que "la tragedia quiere hacernos saber que hay en el hecho mismo de la existencia humana una provocación o una paradoja" ${ }^{29}$, que excede a la caída circunstancial o al accidente que lleva a la ruina del héroe, constituyendo en vez una red intrínsecamente vital. Por otro lado, y obviando las distancias que pueda tener con Steiner, nos parece pertinente contar con el soporte que da Raymond Williams al disponer la tragedia como "una clase específica y una interpretación particular de la muerte y del sufrimiento" ${ }^{30}$, que en último término recae en la constitución irreparable del quiebre y en la confirmación del movimiento perpetuo de la naturaleza. Por último, y ya casi en trazos kierkegaardianos, buscaremos compañía en el reconocimiento de Miguel de Unamuno de aquel "abismo del sentimiento de nuestra mortalidad" ${ }^{31}$, que se ve envuelto en una congoja que luego es iluminada por la búsqueda - y valga aquí la imagen-desesperada de la esperanza.

Kierkegaard parece envolver en cierta medida el mismo espíritu paradójico, sufriente y desesperado. La primera anotación suya que nos llega sobre la tragedia, escrita en su Diario el 22 de noviembre de 1834, nueve años antes que El reflejo de lo trágico antiguo en lo trágico moderno y en un contexto personal bastante agitado, comienza afirmando categóricamente que "lo más sublime de la tragedia consiste en ser malentendido" ${ }^{32}$. Tiempo después, en el período en que comienza a leer la Estética de Hegel y la Poética de Aristóteles, entre 1841 y 1842, resignifica internamente esta incomprensión a partir de la noción dialéctica de disrrelación entre idea y actualidad, entre pensamiento y materialidad. Con esto arriba Kierkegaard a la noción de que "lo estético reconcilia la imaginación"33, extendiendo este alcance en primera instancia literario hacia un nivel existencial

29. G. STEINER, La muerte de la tragedia (Siruela, Madrid, 2011) 111.

30. R. Williams, Tragedia moderna (Edhasa, Buenos Aires, 2014) 32.

31. M. DE UnAmuno, Del sentimiento trágico de la vida (Edición electrónica disponible en: http://www.sacerdotesoperarios.org/libros/Miguel\%20de\%20Unamuno\%20 --20Del\%20sentimiento\%20tr\%C3\%A1gico\%20de\%20la\%20vida.pdf. Consultada el 21 de marzo de 2016) 33.

32. JP: I A 33.

33. JP: IV C 114. 
en que es posible que la reconciliación la ganen más bien el lector o el espectador antes que el poeta. Volveremos sobre este punto al rescatar la distinción entre lo trágico en lo estético y lo trágico en lo metafísico.

La conciencia que se instanciaba en la Antígona moderna, entendida como despertamiento de la reflexión subjetiva y amansadora de la pena hecha dolor, se inscribe precisamente en el radio de aquella ruptura existencial. La búsqueda y la compresión de una salida a este quiebre es el núcleo de toda la producción kierkegaardiana. Desde fohannes Climacus, o De omnibus dubitandum est, un borrador nunca terminado de 1842, hasta La enfermedad mortal de 1849, nos encontramos con distintas reversiones de una "teogénesis de la libertad individual" 34 , que intenta indicar un camino a través del que la acción subjetiva deviene su propio objeto y encuentra el correlato efectivo entre lo ideal y lo actual. Esta disposición toma para Kierkegaard, y para sus seudónimos, los más diversos nombres -conciencia, espíritu, yo, singularidad, individualidad, subjetividad, libertad-, pero mienta en todo momento un interés, un inter-esse, un entre-ser ontológico primero y óntico después, que ejecuta el contenido de la conciencia en la materialidad.

El despliegue de los estadios de la existencia, uno de los lugares comunes de Kierkegaard, es precisamente la encarnación de ese avance que ejecuta la conciencia para llegar al umbral en que la reconciliación se da y se quita a la vez, agenciándose luego como repetición. Los estadios se arraigan en la convicción metafísica de Kierkegaard de que la existencia es un arte, una autocreación ${ }^{35}$. Así, el existir es un momento dialéctico ${ }^{36}$ que resulta de una inmediatez estética, una mediación formal o ética y una segunda inmediatez mediada o religiosa. A lo que intentábamos llegar con la caracteri-

34. M. BinetTI, La posibilidad necesaria de la libertad. Un análisis del pensamiento de Søren Kierkegaard (Universidad de Navarra, Pamplona, 2005) 39.

35. Cf. S. KierKegaARD, Post Scriptum no científico y definitivo a las Migajas filosóficas (Sígueme, Salamanca, 2011) 346. En adelante PS, 346. S. KiERKEGAard, Afsluttende uvidenskabelig Efterskrift, Søren Kierkegaards Skrifter (Søren Kierkegaard Forskningscenteret, Copenhague, 2002) tomo VII, 321. En adelante SKS VII, 321.

36. Cf. PS, 312/SKS 7, 286. 
zación de lo trágico estético como levantamiento de la reflexión era justamente al punto en que se pudiera entrever que la materialidad primera de lo estético en su relatividad constitutiva se puede entender como una instancia originaria de las mismas categorías que luego se juegan en la inmediatez de lo religioso.

No se puede obviar el carácter definitivo que tiene la religión en Kierkegaard, pero hay que disponer ciertos elementos con sumo cuidado hermenéutico para no caer en una infértil incomprensión. El movimiento de lo estético hacia lo ético configura un cambio de cualidad en que la subjetividad únicamente desparramada hacia la materialidad es vertebrada por la aparición del deber. La dificultad es que esta demanda, que emerge de la misma conciencia subjetiva respecto de cierta sustancialidad externa, se le muestra al individuo en su punto crítico como heterogénea, como totalmente discordante con sus capacidades. De esta tensión de la idealidad no llevada a actualidad surge el cariz religioso.

La cuestión se presenta con algo más de claridad cuando se entiende que Kierkegaard dispone al individuo como una "síntesis de infinitud y finitud, de lo temporal y lo eterno, de libertad y necesidad" 37 . En esta traída de elasticidad dialéctica se ponen en pugna categorías derechamente nacidas desde la inmediatez de la estética — finitud, temporalidad y necesidad material - y categorías brotadas luego de que la conciencia avanza y se ejecuta como pura potencia subjetiva en la ética —infinitud, eternidad y posibilidad libre- El espíritu no puede desbalancearse en la proporción de estos contrarios. La finitud detiene el avance de la infinitud, lo temporal de lo eterno y lo necesario de lo posible, y también inversamente, de modo que el hombre ni se pierda en el cielo vacío de lo abstracto ni se hunda en las pantanosas tierras de lo efímero. Surge aquí, pues, la cuestión del sostén metafísico que opera las veces de esqueleto de la realidad existente. Sin las bisagras de lo ideal, la rigidez de lo fáctico se vuelve contra el individuo, y carcome su

37. S. KierkegaARD, La enfermedad mortal (Trotta, Madrid, 2008) 33. En adelante, EM, 33. S. KierKegaARD, Sygdommen til Døden, Søren Kierkegaards Skrifter (Søren Kierkegaard Forskningscenteret, Copenhague, 2006) Tomo XI, 129. En adelante SKS XI, 129. 
sentido y su existencia. Pero resulta que en la conciencia, a pesar de trascender la existencia inmediata, el individuo permanece en la inmanencia de lo singular, sin mediarse en la negación absoluta que lo derive en su posición igualmente absoluta. Lo que descubre la libertad en la proyección del ideal es la negación de lo dado, pero no una negación que trascienda al individuo completo. Tal instancia aparece cuando el yo intenta aventurarse a la concreción existencial de los opuestos unidos en una relación consciente y se da cuenta de que por sus propias fuerzas tal empresa es imposible. A esa altura ya avanzada del desarrollo subjetivo, pero todavía no definitiva, se vuelve necesario que el hombre se apoye "de manera lúcida en el Poder que lo ha creado" 38 . La aparición y la dependencia de esta nueva figura se dan por una negación libre del sujeto, que se elige a sí mismo perdiéndose a sí mismo. Este movimiento de la libertad, en los umbrales de la consumación total, no se ejecuta sino en términos dialécticos, por lo que lo libre es a la vez lo necesario ${ }^{39}$ : la posibilidad se vuelve necesidad allí donde sólo puede poder. En otras palabras, cuando aparece la posibilidad del absoluto que lo puede todo, es necesario que el individuo se elija libremente a sí mismo eligiendo lo otro. De este deber incondicionado, Kierkegaard extrae la posibilidad dialéctica, atravesada por la necesidad dialéctica, para aplicarla a la necesidad de lo fáctico y mediarla en una realidad más alta.

Con esto podemos reflotar la distinción que Kierkegaard presentaba en El reflejo de lo trágico antiguo en lo trágico moderno entre una tragedia estética y una tragedia metafísica. Si bien en lo estético se reconcilia la imaginación, esta reconciliación es únicamente temporal y relativa. Por el contrario, leída la cuestión desde la religión, la mediación y el sostenimiento de los opuestos en la conciencia se dan con una impronta metafísica absoluta, que resignifica la ambi-

38. EM, 34/SKS XI, 129.

39. Cf. JP: X 2 A 418: "Tú debes elegir lo único necesario, pero de modo tal que no se trate de una elección (...) Así, por lo tanto, hay algo respecto de lo que no se debe elegir, y según cuyo concepto no puede ser una elección y que sin embargo es una elección. De allí justamente esto, que no haya ninguna elección expresa con qué intensidad y pasión inmensa se elige (...) El contenido de la libertad es a tal punto decisivo para la libertad que la verdad de la libertad de elección es precisamente admitir que aquí no debe haber una elección, aunque haya una elección”. 
güedad de la inmediatez en una materialidad ahora mediada por la idealidad. De esta forma, el sujeto arriba a un estado de constitución ajeno a la pura mundanidad, agenciando una paradójica encarnación de lo eterno en lo temporal, de lo infinito en lo finito, de lo posible en lo necesario. Aquí se juega un precepto trágico que Steiner pone ante la vista, a saber, que la tragedia configura la imagen de que "el hombre es un huésped inoportuno en el mundo" 40 . El individuo religioso vive en ese fermento constantemente, luchando, por una parte, por mantener en la repetición la intercesión de la conciencia y, por otra, por asumir la existencia en un medio que de por sí se le vuelve extraño. Desde esta segunda arista, y atendiendo a la primera en todo momento, emerge la cuestión de la convivencia humana y del desenvolvimiento del individuo en lo externo, cuestiones ambas que no son accesorias y que representan ulteriormente la verdadera posibilidad de reconciliación subjetiva e intersubjetiva.

\section{IV}

Si nos apegamos a la lectura tradicional y entendemos la religión en Kierkegaard como una dialéctica que se desenvuelve únicamente entre el individuo y Dios, se hace por cierto imposible derivar alguna posibilidad de estructura social del corpus kierkegaardiano. No obstante, esta miopía hermenéutica ha comenzado a ser suprimida y se ha operado en las últimas tres décadas un vuelco hacia una reconstrucción comunitaria de singulares en Kierkegaard, predominantemente desde el terreno religioso. En esta línea, Mark Dooley asume que es "en sus reflexiones sobre religión que la dimensión política y social del pensamiento de Kierkegaard puede ser situada" 41 , apropiando a partir de una "cuasireligiosa fidelidad a la singularidad" 42 el criterio para demarcar una esfera ético-política. Este levantamiento se da, entonces, en la articulación originaria de un conjunto de in-

40. G. STEINER, op. cit., 12.

41. M. Dooley, The Politics of Exodus: Derrida, Kierkegaard, and Lévinas on "Hospitality", en R. PERKINS (ed.), International Kierkegaard Commentary: Works of Love (Mercer, Macon, 1999) 170.

42. Ibidem. 
dividualidades, cuestión que en el ámbito kierkegaardiano es únicamente posible por medio del amor.

Kierkegaard se ve compelido a mantener la exigencia especulativa que tiene como presupuesto del desarrollo del espíritu: cuando se habla de las categorías de la conciencia, la relación nunca se da en dos, sino en tres. En este estado de cosas, debe haber una instancia que emerja como cohesiva en el vínculo entre el sujeto y Dios, y que reconcilie en último término a la subjetiva en la inmanencia diferenciada. A esto tercero Kierkegaard le da el nombre de prójimo y lo presenta directamente como "una determinación puramente espiritual"43, que tiene su origen allí donde la infinita posibilidad de la subjetividad se vuelve aquello que en clave dialéctica se nombra como una necesidad por abundancia. Tal y como se dice del poeta que producir es su necesidad constitutiva, igualmente se dice del individuo cualitativamente dispuesto que, siendo pura subjetividad, necesita desbordarse amorosamente. En este sentido, la alteridad que Kierkegaard emancipa no se da en la marginalidad de una singularidad vacía, sino justamente en medio de toda una construcción metafísica que depende del sujeto, de Dios y de los otros para sostenerse.

La proyección espiritual que rebasa al sí mismo y crea al prójimo no es selectiva ni se dispone en el privilegio comparativo del amor al amante o al amigo. Fuera de una reducción prosaica de la relación humana, el amor kierkegaardiano "no tiene más que un único objeto, el prójimo" 44 y el prójimo no es otra cosa que "todos los seres humanos" 45 . En esta igualdad, gestora del concepto de humanidad $^{46}$, se resuelve la irreductibilidad de los otros y se aplana por fin un suelo de acción comunitaria que adquiere un carácter originario, alcanzando el foco de resolución que inmanentiza la tras-

43. S. KiERKEGAARD, Las obras del amor (Sígueme, Salamanca, 2008) 81. En adelante OA, 81. S. KIERKEGAARD, Kjerlighedens Gjerninger, Søren Kierkegaards Skrifter (Søren Kierkegaard Forskningscenteret, Copenhague, 2004) tomo IX, 63. En adelante SKS IX, 63.

44. OA, 79/SKS IX, 61.

45. OA, Ibidem/SKS IX, 62.

46. JP: VIII 1 A 268: ¿Qué es humanidad? Es la igualdad humana. Inigualdad es lo inhumano. 
cendencia que ha desplegado la conciencia subjetiva. Este vínculo ontológico-óntico en clave dialéctica lo ha atisbado María José Binetti de una manera novedosa y fundamental: la identidad individual que Kierkegaard propone "es esencialmente relacional, por el hecho de fundarse, más allá de sí, en el Otro Absoluto, y de sostenerse, fuera de sí, en los otros" ${ }^{\prime 7}$. Así, el singular kierkegaardiano se mueve en el umbral de una perfección participada, que se acciona más allá de la relatividad de las relaciones inmediatas.

Una distinción crucial que se está jugando aquí es la que existe para Kierkegaard entre la multitud y la comunidad ${ }^{48}$. Cuando Kierkegaard habla de multitud, está apuntando a una reducción óntica de los sujetos, que se cifra en la comparación infinita, en la pérdida de la identidad individual y en la ausencia de responsabilidad. En este ámbito crecen tan sólo la confrontación cuantitativa, la inconsciencia y la predilección encarnada en sus dos modulaciones estéticas: el amor erótico y el amor de amistad. Frente a este panorama, que podemos entender como el de la articulación social y política al nivel de la generalidad, se deslinda una superación dicha por Kierkegaard con el amor cristiano, que opera un vínculo ontológico con los otros, devolviéndoles su rostro y su voz, así como también su infinita responsabilidad existencial. De esta diferencia transida por la igualdad se erige no una duplicación del yo que se ama a sí mismo en un otro yo, sino un primer tú, que es cada ser humano en el género cualitativamente dispuesto $^{49}$. A esta articulación apela Kierkegaard

47. M. BinetTi, El amor: clave de resolución en la dialéctica de la libertad kierkegaardiana, "Revista de filosofía de la Universidad de Zulia" 44/2 (2003) 102.

48. Podemos volver a un pasaje del Diario que citamos al comienzo, JP: VIII 1 A 23: "'La multitud' es a lo que realmente he apuntado de forma polémica, y eso lo aprendí de Sócrates. Quiero volver a los hombres conscientes, de tal modo que no desperdicien y despilfarren sus vidas. Los aristócratas dan por sentado que siempre se da una masa de hombre que van al desperdicio. Pero permanecen callados, viven recluidos, y hacen como si estos muchos, muchos seres humanos no existieran en absoluto. Esta es la debilidad de la exclusividad de los aristócratas - que en orden a tener una vida fácil ellos mismos, no vuelven a la gente consciente". Cf. JP: X 5 245: “(...) el 'individuo singular' debe haber intervenido con decisividad ética como el término medio, en orden a asegurarse que 'comunidad' y 'congregación' no sean tomadas en vano como sinónimos de 'público' o 'multitud', etc.". 49. Cf. OA, 82/SKS IX, 64. 
cuando dice $-\mathrm{y}$ téngase a la vista lo que veíamos el comienzo con Lévinas- que "la contemporaneidad con personas reales, cuando cada una de ellas es algo, en un instante real y en una situación real, fortalece al individuo" $"$.

En último término, la posibilidad de una convivencia intersubjetiva en Kierkegaard, articulable como de índole sociopolítica, no viene a reemplazar el ordenamiento jurídico y estatal de la generalidad, sino a constituir un espacio de comunidad alternativo que se sale del paradigma de la confrontación ${ }^{51}$. Para Kierkegaard, el poder político tradicional comporta la raíz de la aniquilación subjetiva en términos espirituales, más allá de que asegure una cierta comodidad en cuanto a los bienes materiales, y por lo mismo sugiere una trascendencia de ese peligro en una inmanencia cruzada por una proyección espiritual cualitativamente determinante. Esto se logra con aparición de un deber ético a la segunda potencia, que, como sostiene Pia Søltof, se erige como el principio ontológico que Kierkegaard pone detrás de toda posibilidad intersubjetiva. Superando el individualismo de la conciencia individual y, por lo mismo, de la responsabilidad ética, Kierkegaard inserta el amor como una categoría que desde la metafísica condiciona el desenvolvimiento ético, y que resignifica la ética como una esfera en la que se alcanza precisamente una comunidad, cuya materialidad se esfuerza por repetir en todo momento su idealidad ${ }^{52}$.

El lazo amoroso que busca extender Kierkegaard hacia una disposición comunitaria sufre de la misma tensión que la constitución singular. La disrrelación entre idealidad y actualidad que acechaba al individuo se traspasa a la comunidad, toda vez que esta se avisa como soportada por los mismos individuos y sus proyecciones. De esta forma, el registro intersubjetivo kierkegaardiano obliga a la repeti-

50. S. KierKegAARD, La época presente (Universitaria, Santiago, 2001) 74. S. KIERKEGAARD, En literair Anmeldelse, Søren Kierkegaards Skrifter (Søren Kierkegaard Forskningscenteret, Copenhague, 2004) Tomo VIII, 87.

51. Cf. M. DoOley, op. cit., 167-168.

52. Cf. P. Søltoft, A Literary Review: The Ethical and the Social, en J. CappelørN, N. Deuser (eds.), Kierkegaard Studies Yearbook (Walter de Gruyter, Nueva YorkBerlin, 1999) 123. 
ción, a la consumación constante de las categorías que lo demarcan, apartando en todo momento la posibilidad de que una reconciliación estática desfigure la apertura ontológica de los miembros de la comunidad y de la comunidad misma. Bajo este prisma, bien nos viene traer a la colación la forma en que Juan Pablo Arancibia lee la articulación política contemporánea en torno a la comunidad. Concentrándonos en la articulación metafísica que arrastra y dejando de lado las inflexiones históricas ajenas a Kierkegaard, nos parece que disponer lo comunitario como "una relación suspensiva, un riesgo, una posibilidad" ${ }^{53}$ representa un provechoso desciframiento de los impulsos y los abates que controlan la vida de cada sujeto, disponiéndolo en una primera instancia en una relación de conciencia tensada consigo mismo y luego con los demás.

Aquí la apuesta de la tragedia hacia la comunidad en Kierkegaard, desde Steiner, Williams, Unamuno. Desde el reconocimiento de la paradoja y la alienación, desde la respuesta al sufrimiento y a la muerte como signos de lo humano, desde la congoja que busca la esperanza, esto es, desde el despertamiento de la conciencia y desde las rupturas que acompañan el tránsito reflexivo, no hacia una reconciliación dialéctica consumada, sino hacia una lucha constante, hacia el ejercicio repetitivo de asumirse uno mismo como sujeto al tiempo que se desborda subjetividad hacia los otros.

Kierkegaard nos entrega el aparato metafísico y nos invita a una comprensión que ha hecho eco en nuestra época, precisamente cuando la reducción política amenaza en igual medida e impertérritamente tanto lo ontológico como lo óntico. El escape a la confrontación, la vía paralela a la conducción estatal que nos provee el bien material, la posibilidad de revisar en diversos registros las proyecciones que operamos con los otros, todas estas son cuestiones que nos quedan abiertas en el pensamiento y que deberían azuzarnos a reconsiderar las categorías que rigen nuestra convivencia.

53. J. P. ARAncibía CARrizo, Comunidad, Tragedia y Melancolía: Estudio para una Concepción Trágica de lo Político, "Revista Grafía" 10/2 (2013) 118. 


\section{REFERENCIAS}

TH. Adorno, Kierkegaard. Construcción de lo estético, Obras completas (Madrid, Akal, 2006) tomo II.

J. P. ArancibÍa Carrizo, Comunidad, Tragedia y Melancolía: Estudio para una Concepción Trágica de lo Politico, "Revista Grafía" 10/2 (2013) 111-142.

Aristóteles, Poética (Gredos, Madrid, 1974).

M. BinetTi, El amor: clave de resolución en la dialéctica de la libertad kierkegaardiana, "Revista de filosofía de la Universidad de Zulia" 44/2 (2003) 85-104.

M. BinetTi, La posibilidad necesaria de la libertad. Un análisis del pensamiento de Søren Kierkegaard (Universidad de Navarra, Pamplona, 2005).

P. CutTING, The Levels of Interpersonal Relationships in Kierkegaard's Two Ages, en R. PERKIns (ed.), International Kierkegaard Commentary: Two Ages (Mercer University Press, Macon, 1984).

M. Dooley, The Politics of Exodus: Derrida, Kierkegaard, and Lévinas on "Hospitality", en R. PERKINs (ed.), International Kierkegaard Commentary: Works of Love (Mercer, Macon, 1999).

G. W. F. HegeL, Vorlesungen über die Aesthetik (Druncker und Humblot, Berlin, 1838) Tomo III.

C. Holler, Tragedy in the Context of Kierkegaard's Either/Or', en R. PERKINs (ed.), International Kierkegaard Commentary: Either/ Or, I (Mercer, Macon, 1995).

S. KIERKEgAarD, Søren Kierkegaard's fournals and Papers (Indiana University Press, Bloomington, 1967-1978) 7 vols.

S. KierKegaARD, Enten-Eller. Søren Kierkegaards Skrifter (Søren Kierkegaard Forskningscenteret, Copenhague, 1997) tomo II.

S. KierKegaARD, La época presente (Universitaria, Santiago, 2001).

S. KIERKEgaARD, Afsluttende uvidenskabelig Efterskrift, Søren Kierkegaards Skrifter (Søren Kierkegaard Forskningscenteret, Copenhague, 2002) tomo VII.

S. KIERKEgAARD, En literair Anmeldelse, Søren Kierkegaards Skrifter (Søren Kierkegaard Forskningscenteret, Copenhague, 2004) tomo VIII. 
S. KIERKEGAARD, Kjerlighedens Gjerninger, Søren Kierkegaards Skrifter (Søren Kierkegaard Forskningscenteret, Copenhague, 2004) tomo IX.

S. KierkegaARD, O lo uno o lo otro (Trotta, Madrid, 2006).

S. KierKegaARD, Sygdommen til Døden, Søren Kierkegaards Skrifter (Søren Kierkegaard Forskningscenteret, Copenhague, 2006) tomo XI.

S. KieRKEGAARD, La enfermedad mortal (Trotta, Madrid, 2008).

S. KIERKEgAARD, Las obras del amor (Sígueme, Salamanca, 2008).

S. Kierkegaard, Post Scriptum no cientifico y definitivo a las Migajas filosóficas (Sígueme, Salamanca, 2011).

E. LÉvinas, Proper Names (Stanford University Press, Stanford, 1996).

R. Perkins (ed.), International Kierkegaard Commentary: Two Ages (Mercer, Macon, 1984).

P. Søltoft, A Literary Review: The Ethical and the Social, en J. CAPPELØrn, N. Deuser (eds.), Kierkegaard Studies Yearbook (Walter de Gruyter, New York-Berlin, 1999).

G. STEINER, La muerte de la tragedia (Siruela, Madrid, 2011).

J. STEWART, Kierkegaard's Relations to Hegel Reconsidered (Cambridge University Press, Cambridge, 2003).

M. DE Unamuno, Del sentimiento trágico de la vida (Edición electrónica disponible en: http://www.sacerdotesoperarios.org/ libros/Miguel\%20de\%20Unamuno\%20--20Del\%20sentimiento \% 20tr\%C3\%A1 gico\%20de\%20la\%20vida.pdf. Consultada el 21 de marzo de 2016).

R. Williams, Tragedia moderna (Edhasa, Buenos Aires, 2014). 
